\title{
BATHYMETRY FROM WORLDVIEW-3 SATELLITE DATA USING RADIOMETRIC BAND RATIO
}

\author{
Claudio Parente*, Massimiliano Pepe
}

\author{
Department of Sciences and Technologies, University of Naples "Parthenope", 80143, Naples, Italy \\ * corresponding author: claudio.parente@uniparthenope.it
}

\begin{abstract}
The use of optical satellite sensors allows to obtain bathymetry data on large area in a short time and in a cheap way. In addition, in particular places where it is difficult to carry out the survey by classic methods, the bathymetry from satellite data can be the only mode to obtain the depth of the backdrop. So, the aim of this research paper is to analyse the potential of the eight bands and the very high resolution of the commercial satellite WorldView-3 (WV-3) in order to obtain bathymetric data.

Using WV-3 satellite data and the Stumpf method, the paper intends to investigate the possibility of obtaining bathymetric data in a specific area where the water is not particularly clear. To achieve this goal, in Geographic Information System (GIS) environment, several algorithms have been developed.

The comparison between the results and the reference bathymetric data shows a huge potential of the WV-3 satellite data. The area of study concerns the port area of the city of Lisbon and a part of the river Rio Tejo, in Portugal.
\end{abstract}

KEYWORDS: bathymetry; SDB; WorldView-3; spectral bands; satellite atmospheric correction; remote sensing.

\section{INTRODUCTION}

Based on the statistical relationships between satellite image pixel values and field measured water depth measurements, several methods in Remote Sensing (RS) environments have been developed in order to obtain bathymetric data of a specific area of study.

Indeed, Satellite Derived Bathymetry (SDB) is one of the main areas of research in the field of the RS of the marine environment considering the numerous practical applications: monitoring underwater topography, movement of deposited sediments and production of maritime charts for navigation [1].

Over the years, different empirical models have been developed in the SDB application, largely connected to the evolution of satellite platforms [2]. In this way, several studies on the ability to estimate depth from a satellite image have been realized using Landsat TM [3], SPOT [4] and QuickBird [5] images. Most recently, DigitalGlobe's WorldView-2 satellite sensor (WV-2), allowed the estimation of water depths thanks to the ability of this sensor to acquire eight bands with a high geometric resolution. In particular, the coastal band, whose wavelength varies from 400 to $450 \mathrm{~nm}$, improves the quality of the bathymetric measure [6]. Indeed, this part of the spectrum provides the deepest penetration of water. Subsequently, in August 2014, the WorldView-3 satellite was launched with a sensor on board that is able to acquire images in eight bands, in a way similar to the WV-2 satellite, but with a greater resolution in the Panchromatic (PAN) and Multispectral (MS) mode [7. Therefore, considering the good results obtained with the WV-2 sensor, in this paper, we investigate the impacts of the high geometric resolution obtained with this new satellite sensor (WV-3), in order to construct bathymetric maps.

The paper is organized as follows. The section entitled "Data and methods" illustrates the characteristics of the WV-3 images and the methods present in literature in order to determine the depth of water by satellite imagery. Subsequently, a suitable workflow is identified in order to obtain bathymetric data. The section "Application of the method on the area of study" explains, by a case study, the accuracy of the bathymetry obtained by WorldView-3 satellite image. Conclusions are summarized at the end of the paper.

\section{DATA AND METHOD}

\subsection{WORLDVIEW-3 DATA}

The latest generation of commercial satellite sensors provides images with a Very High geometric Resolution (VHR), i.e., images with metric and sub-metric spatial resolution. An example of the VHR commercial satellite is the WorldView-3 (WV-3). It collects data with a nominal ground sample distance of $0.31 \mathrm{~m}$ (panchromatic), $1.24 \mathrm{~m}$ (multispectral) and $3.7 \mathrm{~m}$ (Shortwave Infrared - SWIR) at nadir configuration [8, 9]. However, the commercial images are resampled to $0.3 \mathrm{~m}(\mathrm{PAN}), 1.2 \mathrm{~m}(\mathrm{MS})$ and $7.5 \mathrm{~m}$ (SWIR).

Regarding radiometric aspects, the WV-3 acquires 11-bit data in 9 spectral bands covering panchromatic and multispectral bands. The single-wavelength band for a PAN image is $450-900 \mathrm{~nm}$ while the MS images have eight wavelength bands (Figure 1): Coastal (B1: 


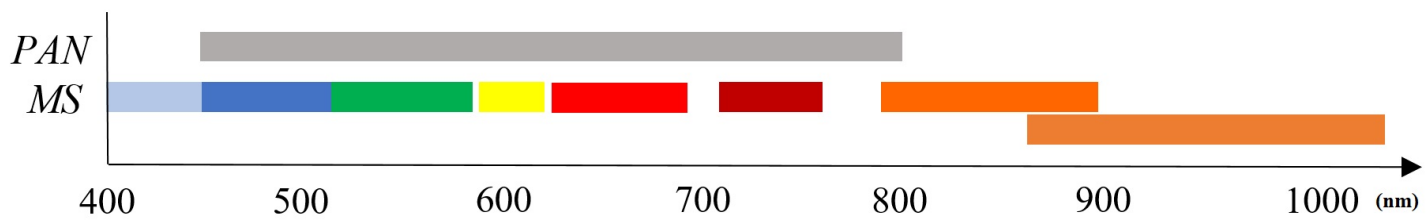

Figure 1. Wavelengths of PAN and MS of WV-3 satellite data in the ranges from 400 to $1040 \mathrm{~nm}$

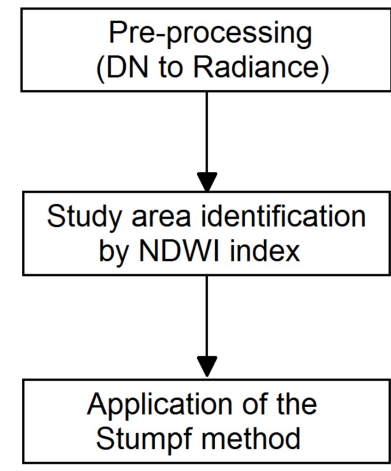

FIGURE 2. SDB workflow.

400-450 nm), Blue (B2: 450-510 nm), Green (B3: 510$580 \mathrm{~nm})$, Yellow (B4: 585-625 nm), Red (B5: 630$690 \mathrm{~nm})$, Red Edge (705-745 nm), Near Infrared 1 (NIR1, B7: 770-895 nm), Near Infrared 2 (NIR2, 860$1040 \mathrm{~nm})$.

The WV-3 data are available in different products depending on a geometry configuration, geo-referenced or not geo-referenced image, type of Digital Elevation Model (DEM) used for the geo-referencing, stereo images and presence of additional files for the implementation in a specific package software. In particular, the several satellite data available are described as follows 10]:

- Basic (1B) Imagery is corrected for radiometric distortions, internal sensor geometry, optical distortions and sensor distortions but it is neither geo-referenced nor mapped to a cartographic projection.

- Standard (2A) Imagery is radiometrically corrected, sensor corrected, and projected to a plane using the map projection and datum of the customer's choice. Standard Imagery also has a coarse DEM applied to it, which is used to rectify data in consideration of topographic relief and the reference ellipsoid. All Standard Imagery products have a uniform Ground Sample Distance (GSD) throughout the entire product.

- OrthoReady (2A) Imagery contains all the characteristics of the Standard (2A) product and it is projected to a constant base elevation, which is calculated on the average terrain elevation of the Area of interest (AOI).

- Basic (1B) Stereo Imagery contains all the characteristics of the Basic 1B Product; however, two images are delivered with a $100 \%$ overlap over the AOI. Stereo pairs are collected on the same satellite orbit and with specific look angles in order to attain an imagery appropriate for stereo viewing. In addition to the standard metadata files of a Basic product, a *.STE file is delivered to orient the stereo pairs in photogrammetric software packages for further analysis and elevation extraction.

- OrthoReady (2A) Stereo Imagery has the same physical structure as Ortho-Ready Standard Imagery products. Ortho Ready Stereo Imagery products offer a $100 \%$ stereo coverage over the AOI. In addition to the standard metadata files of an Ortho Ready $2 \mathrm{~A}$ product, a *.STE file is delivered to orient the stereo pairs in photogrammetric software packages for further analysis and elevation extraction.

\subsection{Procedure FOR BATHYMETRIC DATA}

In order to obtain the depth of the water from a satellite image, it was necessary to perform several steps. In general, the first step is to transform the Digital Number $(D N)$ of the image in physical information using several procedures. This task is known as the "pre-processing" of the image [11, 12] and it is discussed in the next section.

After the pre-processing, the next task is the identification of the study area, or better the determination of the region with only water. This task can be realized manually or by a suitable algorithm. In this study, in order to discriminate only the water area, the NDWI (Normalized Difference Water Index) [13 15$]$ was applied. Using VW-3 image, the index formula becomes 16

$$
N D W I=\frac{\text { Coastal }-N I R 2}{\text { Coastal }+ \text { NIR2 }} .
$$

Lastly, in ArcGIS environment, the Stumpf [17] method was implemented. This task requires a special procedure, which involves a further workflow (widely described in the next paragraph).

So, summarizing the several steps, it is possible to build the workflow, see Figure 2 .

\subsection{Pre-Processing SATEllite WV-3 DAta: FROM DIGITAL NUMBER TO REFLECTANCE}

The aim of the radiometric correction of space-borne imagery by optical sensors is the extraction of physical earth surface parameters 18. In addition, many causes, such as the variability in detector response, 


\begin{tabular}{lcc}
\hline \multicolumn{1}{c}{ Band } & Gain & Offset \\
\hline Pan & 0.923 & -1.700 \\
Coastal & 0.863 & -7.154 \\
Blue & 0.905 & -4.189 \\
Green & 0.907 & -3.287 \\
Yellow & 0.938 & -1.816 \\
Red & 0.945 & -1.350 \\
Red Edge & 0.980 & -2.617 \\
NIR1 & 0.982 & -3.752 \\
NIR2 & 0.954 & -1.507 \\
\hline
\end{tabular}

TABle 1. Absolute radiometric Calibration Adjustment Factors for WorldView-3.

variability in electronic gain and offset, lens falloff and particulate contamination on the focal plane generate a not-uniform image in terms of raw DNs. Therefore, in order to convert the raw DNs in radiance, it is necessary to carry out more operations.

First, it is necessary to calibrate the Digital Number $(D N)$ values by the following equation [19]:

$$
L=G D N\left(\frac{a_{\mathrm{f}}}{e_{\mathrm{b}}}\right)+k,
$$

where $L$ - sensor radiance; $G$ - gain; $D N$ - digital number; $a_{\mathrm{f}}$ - abscale factor, $e_{\mathrm{b}}$ - effective bandwidth, $k$ - offset.

The Gain and Offset are the absolute radiometric calibration band dependent adjustment factors whose values are generally reported in a specific table supplied by the imagery provider. However, it is important to emphasize that these are not necessarily static values and they are periodically revisited. In the case of WV-3 images, the Gain and Offset values are reported in the Table 1

The effective bandwidth for each band of the WorldView-3 system is defined by the integral [20]

$$
\Delta \lambda=\int_{0}^{\infty} R^{\prime}(\lambda) d \lambda,
$$

where $\Delta \lambda-$ effective bandwidth, expressed in $\mu \mathrm{m}$, for a given band; $R^{\prime}(\lambda)$ - relative spectral radiance response for a given band.

The effective WorldView-3 bandwidth for each band, extracted from the VW-3 Technical note [21], is listed in Table 2

The conversion from radiance to reflectance can be performed by several methods [22. A widespread method is called Second Simulation of a Satellite Signal in the Solar Spectrum (6S) 23. This method is an advanced radiative transfer code designed to simulate the reflection of solar radiation by a coupled atmosphere-surface system for a wide range of atmospheric, spectral and geometrical conditions [24. The formula that allows this conversion is [25-27]:

$$
\varrho_{\lambda}=\frac{L_{\lambda} d^{2} \pi}{E_{\lambda} \cos \theta_{\mathrm{s}}},
$$

\begin{tabular}{lcc}
\hline Band & $\begin{array}{c}\text { Center } \\
\text { Wavelength } \\
(\mathrm{nm})\end{array}$ & $\begin{array}{c}\text { Effective } \\
\text { Bandwidth } \\
\Delta \lambda(\mu \mathrm{m})\end{array}$ \\
\hline Pan & 649.4 & 0.2896 \\
Coastal & 427.4 & 0.0405 \\
Blue & 481.9 & 0.0540 \\
Green & 547.1 & 0.0618 \\
Yellow & 604.3 & 0.0381 \\
Red & 660.1 & 0.0585 \\
Red Edge & 722.7 & 0.0387 \\
NIR1 & 824.0 & 0.1004 \\
NIR2 & 913.6 & 0.0889 \\
\hline
\end{tabular}

TABLE 2. WorldView-3 Effective Bandwidths.

\begin{tabular}{clc}
\hline $\begin{array}{c}\text { Band } \\
\text { number }\end{array}$ & Band & $\begin{array}{c}\text { Spectral Irradiance } \\
\left(\mathrm{W} \mathrm{m}^{2} \mathrm{~nm}^{-1}\right)\end{array}$ \\
\hline- & Pan & 1574.41 \\
B1 & Coastal & 1757.89 \\
B2 & Blue & 2004.61 \\
B3 & Green & 1830.18 \\
B4 & Yellow & 1712.07 \\
B5 & Red & 1535.33 \\
B6 & Rede Edge & 1348.08 \\
B7 & NIR1 & 1055.94 \\
B8 & NIR2 & 858.77 \\
\hline
\end{tabular}

TABle 3. Band-Averaged Solar Spectral Irradiance.

where $L_{\lambda}$ - sensor radiance for the spectral band $\lambda ; \varrho_{\lambda}$ - sensor reflectance for the spectral band $\lambda$; $d$ - Earth-Sun distance in astronomical units; $E_{\lambda}$ band-averaged solar exoatmopsheric irradiance; $\theta_{\mathrm{s}}$ solar zenith angle.

The reflectance values range from 0 to 1 [28] and its use allows the compensation for different values of the exoatmospheric solar irradiance arising from spectral band differences and the correction for the variation in the Earth-Sun distance between the different acquisitions [29].

Regarding the band-averaged solar spectral irradiance, it can be defined as the weighted average of the peak normalized effective irradiance value over the detector bandpass as shown in the following equation 30]:

$$
E_{\text {sun }, \lambda \text { Band }}=\frac{\int_{0}^{\infty} E_{\text {sun }} R^{\prime}(\lambda)_{\text {Band }} d \lambda}{\int_{0}^{\infty} R^{\prime}(\lambda)_{\text {Band }} d \lambda},
$$

where $E_{\text {sun }, \lambda \text { Band }}$ - band-average solar spectral irradiance for a given band; $E_{\text {sun }}$ - solar spectral irradiance curve; $R^{\prime}(\lambda)_{\text {Band }}$ - relative spectral radiance response for a given band.

The values of band-averaged solar spectral irradiance used for the Atmospheric Correction (AC) are reported in Table 331 .

In order to calculate the Earth-Sun distance for each satellite image, it is necessary to calculate the Julian 


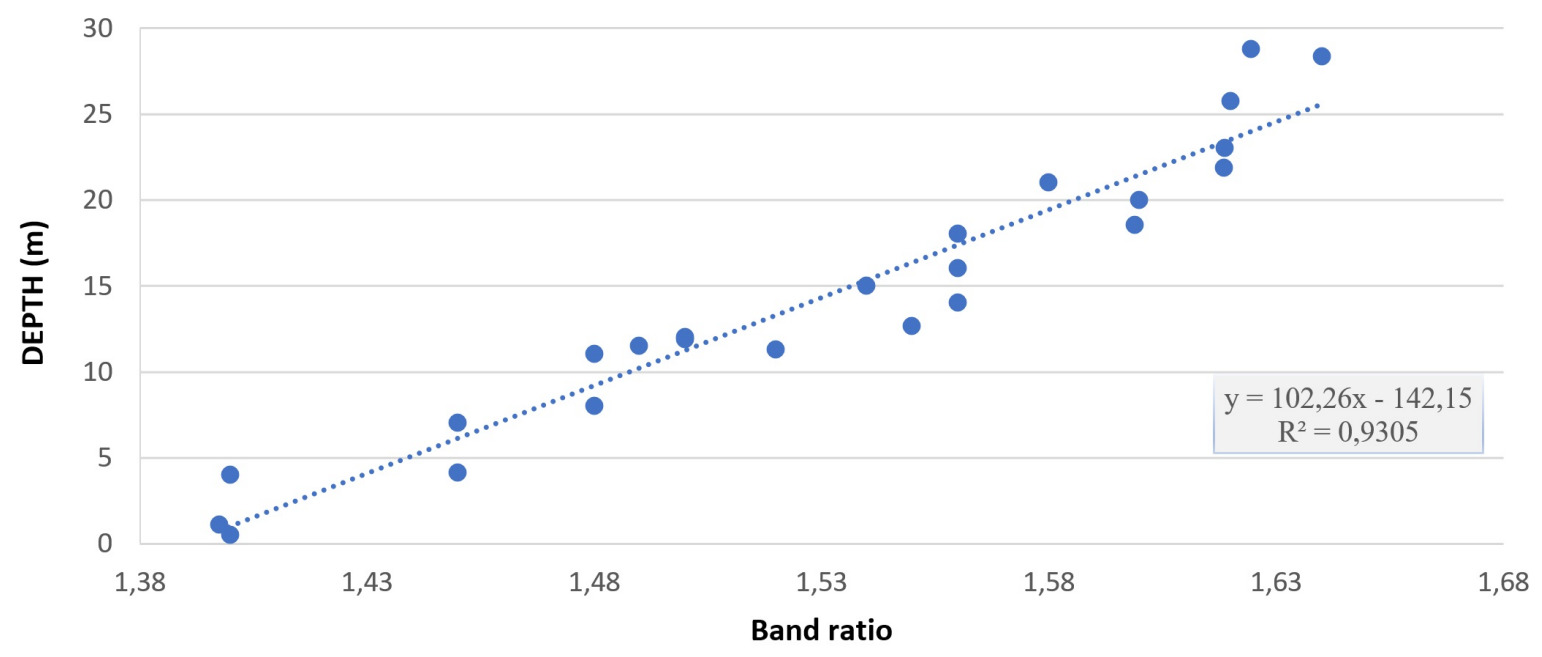

FiguRE 3. Hypothetic graph of the depth (vertical axis) respect to band ratio (horizontal axis).

Day by the acquisition time (expressed in UTM time) that is contained in the image metadata file $(*$. IMD extension). Once the Julian Day ( $J D)$ is calculated, the Earth-Sun distance $\left(d_{\mathrm{ES}}\right)$ is obtained using the following equation:

$$
d_{\mathrm{ES}}=1.00014-0.0167 \cos g-0.00014 \cos 2 g,
$$

where

$$
g=357.529+0.98560028 D
$$

and

$$
D=J D-2451545.0 .
$$

The solar zenith angle is complementary to the sun elevation (sunEl) angle (mean value) and this latter value can be extracted from the image metadata file. Therefore, the formula for the solar zenith angle is

$$
\theta_{\mathrm{s}}=90^{\circ}-\operatorname{sunEl} .
$$

\subsection{The Lyzenga And the StumpF METHODS}

The first study on the possibility to use a satellite image in order to determine the water depth was proposed by Lyzenga. The empirical method developed by the author, in the hypothesis of water properties homogeneous and Beer's law (light decays exponentially with depth in the water column), allows to determine the water depth by a linear equation

$$
Z=a_{0}+a_{i} \varrho_{i}+a_{j} \varrho_{j},
$$

where $a_{0}, a_{i}, a_{j}$ - constants of the regression (determined from linear regressions); $\varrho_{i}, \varrho_{j}$ — transformed reflectance at a specific band.

In order to have the linearity transformation, the natural logarithm can be used to linearize the reflectance 32]:

$$
X_{i}=\ln \left(n \varrho_{\mathrm{w}}\left(\lambda_{i}\right)-n \varrho_{\infty}\left(\lambda_{i}\right)\right),
$$

where $\varrho_{\mathrm{w}}\left(\lambda_{i}\right)$ - water column reflectance; $\varrho_{\infty}\left(\lambda_{i}\right)$ reflectance of water.
However, Lyzenga's method is inaccurate for calculating water depth since the bottom albedos varied significantly [33] and when the depth is greater than 15 meters [18. A method able to overcome these limitations was developed by Stumpf et al. (2003) based on absorption degrees of different bands with different wavelengths. In this method, considering the ratio of reflectance bands, the depth can be obtained by the following equation:

$$
Z=m_{1} \frac{\ln \left(n \varrho_{\mathrm{w}}\left(\lambda_{i}\right)\right)}{\ln \left(n \varrho_{\mathrm{w}}\left(\lambda_{j}\right)\right)}-m_{0},
$$

where $m_{1}$ - constant to scale the ratio to depth; $n$ - fixed constant for all areas to assume that the algorithm is positive; $m_{0}$ - offset for a depth of $0 \mathrm{~m}$ where $Z=0 ; \varrho_{\mathrm{w}}$ - reflectance of water; $\lambda_{i}, \lambda_{j}$ - two different bands.

Using this method, a linear regression for the reflectance ratio between two bands and Ground Truth (the effective depth that can be expressed by DEM) must be developed. For example, considering a transect where the values of reflectance and real depth are known, reporting these values in a graph, it is possible to build the correlation between the parameters investigated (Figure 3).

In this way, it is possible to calculate the value of the linear regression and to analyse the quality of the linear regression. A method that allows to analyse the quality of a regression is the coefficient of determination, also called multiple correlation coefficient [34]. In the case shown in Figure 3 the high value of the coefficient of determination $\left(R^{2}=0.9305\right)$ means a strong relationship between the ground truth data and the bathymetric model. The coefficient of the determination ranges from 0 to 1 ; if its value is equal to 1 , it means that the regression line perfectly fits the data, while if its value is equal to 0 , the data are not correlated. 

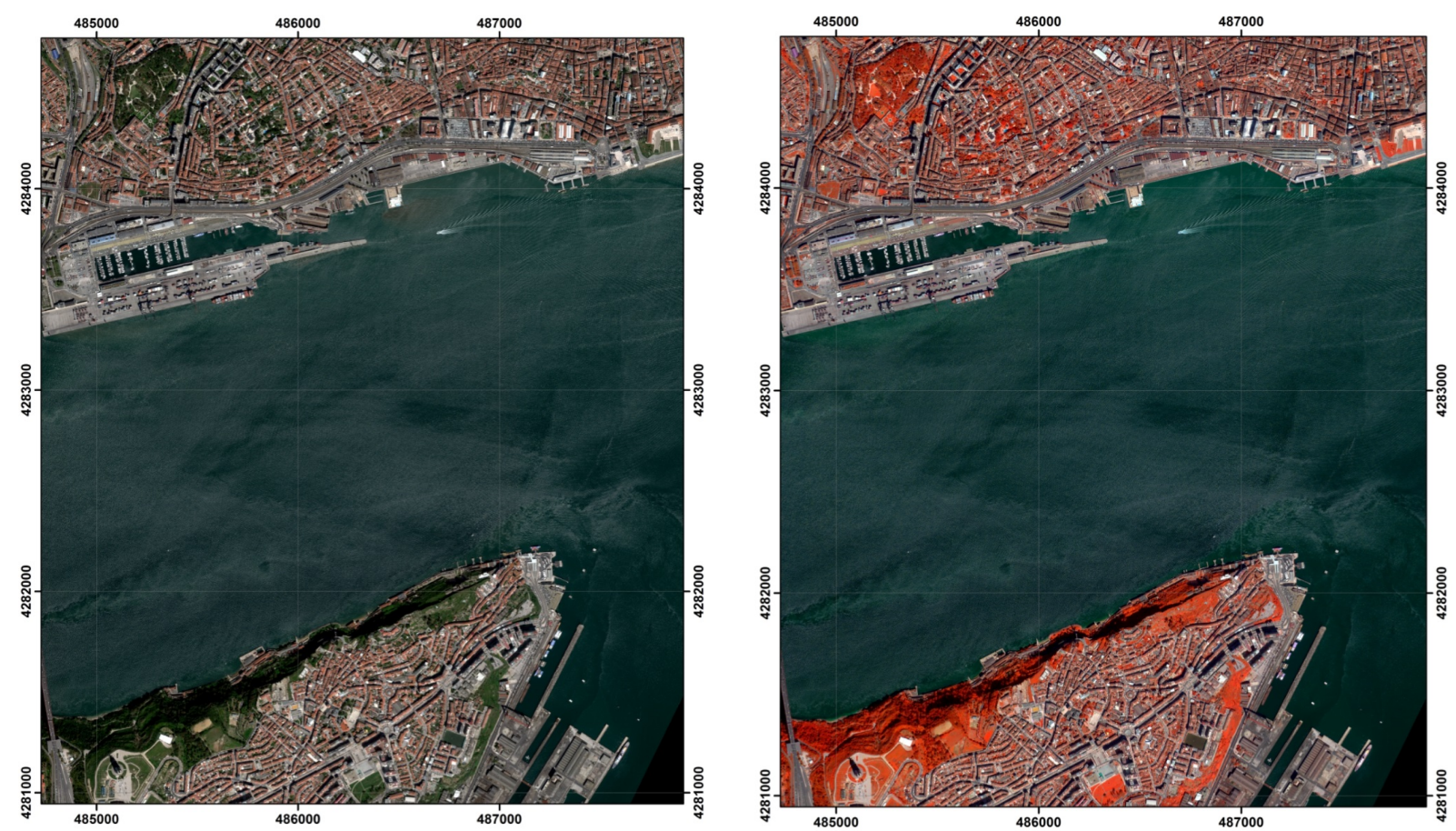

Figure 4. Study area: Multispectral scene of Worldview-3 in Transverse Mercator Projection (WGS 1984 UTM Zone 29N). a) RGB: 5-3-2 composite bands; b) MultiSpectral: 7-3-1 composite bands.
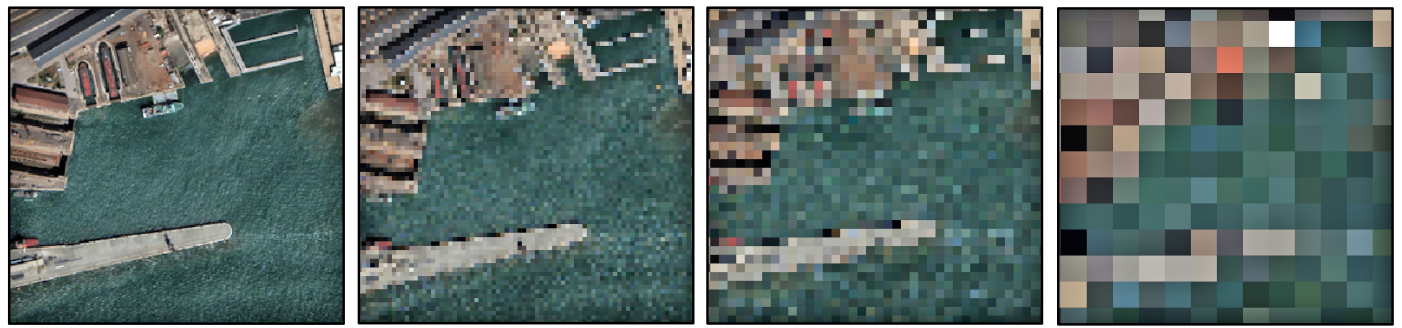

FigURE 5. Several geometry resolutions of the same area: a) $G S D=1.2 \mathrm{~m}$; b) $G S D=5 \mathrm{~m} ; G S D=10 \mathrm{~m}$; $G S D=30 \mathrm{~m}$

\section{Application of the Method \\ ON THE STUDY AREA}

\subsection{STUDY AREA}

The study area concerning the part of the river called Rio Tejo near Lisbon (9॰09' 46" N and 38 41'38" E), in the south east of Portugal (Figure 4). This area is covered by WV-3 satellite data whose dataset is freely available on the Digital Globe website. The Table 4 shows the main information contained in the image metadata file.

Beyond the potential of the new bands in recent satellite missions (Coastal, Yellow, NIR2 bands), an important role is connected to the geometric resolution. Indeed, the very high resolution allows a better detailed description of the AOI, such as the ports, piers and other infrastructures. For example, in Figure 5 it is shown how, taking into account a sample area of about $400 \times 400 \mathrm{~m}$ of the study area, the high resolution of the satellite data allows an extrapolation of depth information even in critical areas.

\begin{tabular}{ll}
\hline Feature & Attribute \\
\hline Band ID & Multi \\
$\begin{array}{l}\text { Pan-sharpening } \\
\text { algorithm }\end{array}$ & None \\
Number rows & 5274 \\
Image descriptor & Stereo OR2A \\
Number columns & 5217 \\
Product level & Stereo OR2A \\
Product type & Stereo \\
Stereo Or2a DEM & \\
$\quad$ correction & Base Elevation \\
Terrain height & $97.80 \mathrm{~m}$ \\
Generation time & $2015-05-13 \mathrm{~T} 09: 44: 32 \mathrm{Z}$ \\
Mean sun elevation & $52.9^{\circ}$ \\
Mean collectedcol GSD & $1.271 \mathrm{~m}$ \\
\hline
\end{tabular}

TABLE 4. Main information contained in the *. IMD file. 


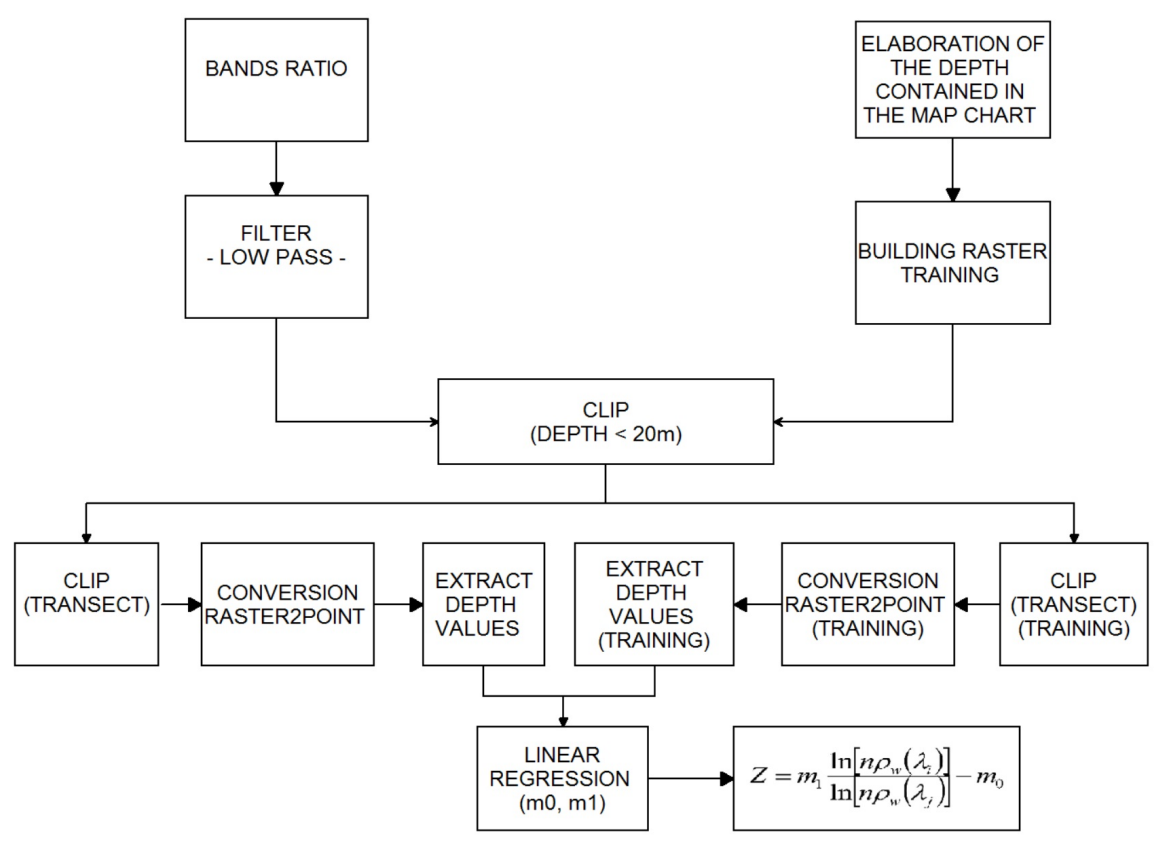

FiguRE 6. Workflow to extract bathymetric data.
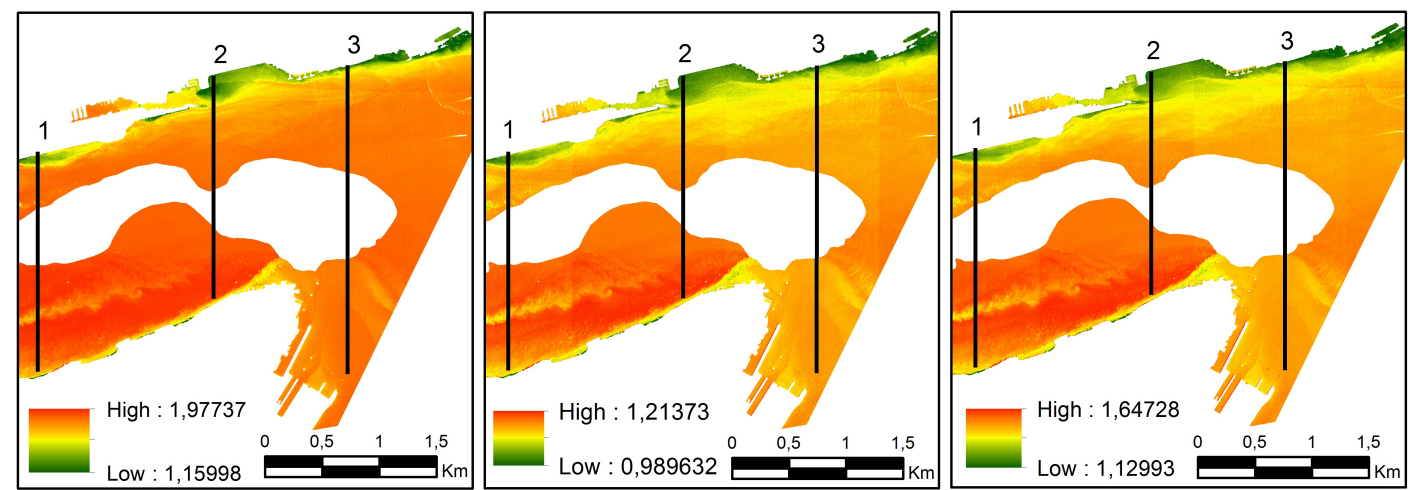

FiguRE 7. Maps of different bands ratio in green-red scale (ratio radiances): a) ratio of Coastal and Yellow bands; b) ratio of Green and Blue bands; c) ratio of Coastal and Green bands.

\subsection{Application of the Stumpf method}

Once the reflectance data and the region waters under investigation were identified (by NDWI index), it was possible to apply the Stumpf's method using a special procedure sketched in the Figure 6. In particular, in ArcGIS environment, several algorithms that contribute to produce bathymetric data were developed. The first operation carried out was the building of maps derived from the ratio of several bands according to the middle part of 12 . In particular, three different scenarios were created:

- ratio of Coastal and Yellow bands;

- ratio of Green and Blue bands;

- ratio of Coastal and Green bands.

Subsequently, in order to reduce a local variation and remove noise, a low pass filter (LPF) was applied to three different maps [31]. LPF, implemented in
ArcMap software, calculates the average (mean) value for each $3 \times 3$ neighbourhood. The three images obtained in this way (Figure 7), show the band ratio values obtained in depths lower than $20 \mathrm{~m}$. The three transects taken into consideration were reported (black lines) on the three maps.

Along the transects, by a clip operation, band ratio values were extracted from the three different raster files. The values of each transect were transformed in feature points and exported in Microsoft Excel data in order to find the correlation between these series data and the training depth dataset. The points used for the linear regression were extracted from nautical charts, available on the Navionics website. The depth of the AOI ranges from 0 to $36 \mathrm{~m}$. However, the effective study area was limited to the depth less than $20 \mathrm{~m}$, taking into account the experience in the literature and the indication by Digital Globe Company; 

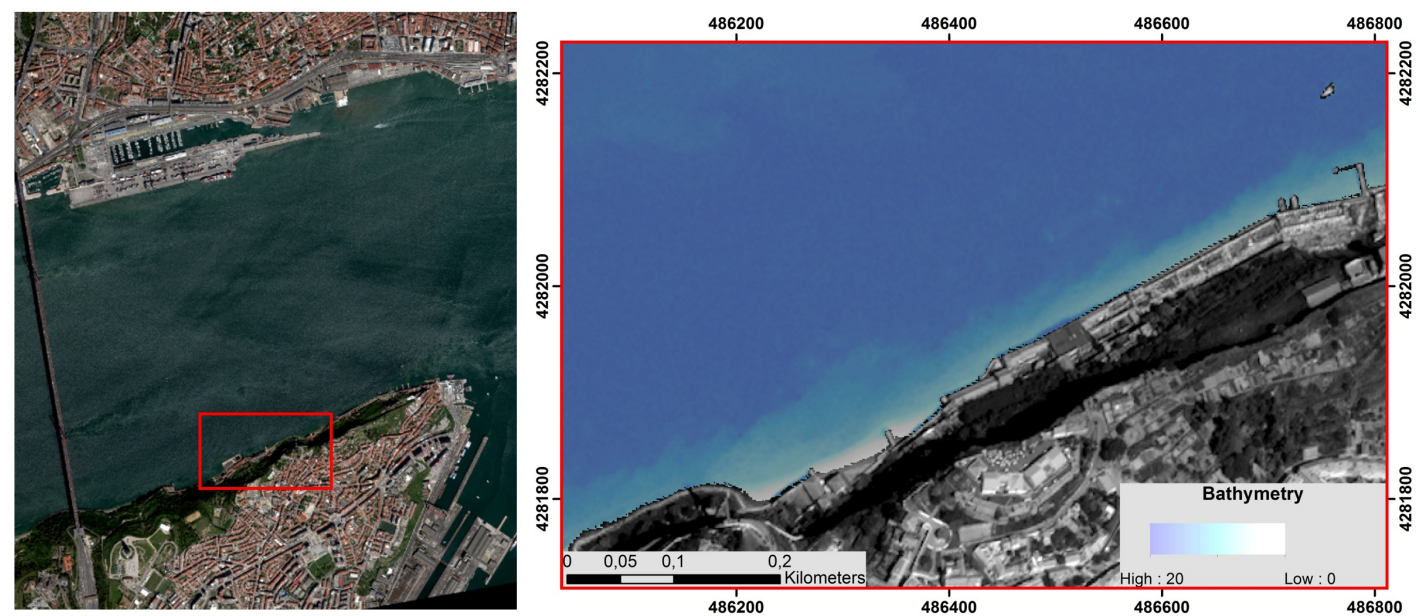

Figure 8. Bathymetry of a zone within in the AOI.

\begin{tabular}{ccc}
\hline Ratio bands & \multicolumn{2}{c}{ Regression Line } \\
\cline { 2 - 3 } & Equation & $R^{2}$ \\
\hline B3 and B1 & $139.35 x-177.69$ & 0.675 \\
B3 and B2 & $257.01 x-275.02$ & 0.534 \\
B4 and B1 & $56.64 x-75.66$ & 0.726 \\
\hline
\end{tabular}

TABLE 5. Regression values of the Transect 1.

\begin{tabular}{ccc}
\hline Ratio bands & \multicolumn{2}{c}{ Regression Line } \\
\cline { 2 - 3 } & Equation & $R^{2}$ \\
\hline B3 and B1 & $138.95 x-180.01$ & 0.793 \\
B3 and B2 & $256.63 x-277.22$ & 0.784 \\
B4 and B1 & $56.63 x-77.87$ & 0.794 \\
\hline
\end{tabular}

TABLE 6. Regression values of the Transect 2 .

\begin{tabular}{ccc}
\hline Ratio bands & \multicolumn{2}{c}{ Regression Line } \\
\cline { 2 - 3 } & Equation & $R^{2}$ \\
\hline B3 and B1 & $135.47 x-176.55$ & 0.560 \\
B3 and B2 & $257.68 x-260.88$ & 0.601 \\
B4 and B1 & $56.57 x-79.99$ & 0.602 \\
\hline
\end{tabular}

TABLE 7. Regression values of the Transect 3.

obviously, this limit value must be connected to the clearance of the waters 32 .

By processing the bathymetric data from the nautical charts suitable for the test area, it was possible to build (in ArcGIS environment) the raster of depths. This map represents the training depths useful for the development of the procedure indicated in the previous workflow.

Comparing the values obtained by bands ratio and training reference data, it was possible to define the correlation between the series data, as shown in Tables 5 , 7 .

The regressions obtained in the three transects

\begin{tabular}{lr}
\hline$\Delta$ Minimum $(\mathrm{m})$ & -7.831 \\
$\Delta$ Maximum $(\mathrm{m})$ & 7.671 \\
$\Delta$ Average $(\mathrm{m})$ & 0.566 \\
$\Delta$ Root Mean Square Error $(\mathrm{m})$ & 3.747 \\
\hline
\end{tabular}

TABle 8. Accuracy on the check points in the depth range $0-20 \mathrm{~m}$.

have shown a good correlation in terms of $R^{2}$ values, especially those achieved on the transect 2 . Also, using the equation of the last line in Table 6 $(Z=56.63 x-77.87)$, the bathymetry from the satellite data was extracted. In Figure 8 , the values of depth along a part of the AOI in the range of depth from 0 to $20 \mathrm{~m}$ is showed.

In order to estimate the accuracy of the method and procedure tested, the difference $(\Delta)$ between the modelled depth $\left(Z_{\text {est }}\right)$ and field-measured depth $\left(Z_{\text {ref }}\right)$ was calculated. The reference points were obtained using the SONAR (SOund NAvigation and Ranging) data. In particular, 47 check points distributed evenly in the area under the investigation were taken in consideration. The $Z_{\text {est }}$ values were extracted from the bathymetric data generated by the Stumpf method. Therefore, in relation to the difference values $(\Delta)$, the statistic parameters (minimum, maximum, average and root mean square error) were calculated (Table 8 ).

\section{Conclusions}

The Stumpf method is an efficient tool to extract bathymetric data from WV-3 satellite imagery. Indeed, thanks to the ability of the WV-3 sensor to capture in the Coastal and Yellow bands, it was possible to achieve the depth of the bottom with a greater accuracy compared to those obtainable with other bands. Indeed, as can be seen from Tables 507 , the best result in term of $R^{2}$ has been obtained by the ratio of these bands. However, the Stumpf method shows some limits, such as the limit of the depth and the needs to know a transect of the real data. In the 
first case, the limit of the depth cannot be fixed $a$ priori, but it must be determined by several simulations in different transects. In this way, it is possible to observe the correlation of the ratio bands and true DEM varying the depth. In the second case, the need to know a transect of the real data leads to carrying out a survey with another method, such as SONAR, Airborne Hydrographic Laser Scanner (AHLS), Global Navigation Satellite System (GNSS) or other techniques. This task could lead to further errors in the measurement of the depth, especially if these data are not acquired correctly.

In addition, the presence of elements that alter the measurement derived by satellite optical images, such as boats, ships and waves, involves an error in the measurement of the depth. Indeed, as shown in Tables 5 7. we have obtained different values of the linear regression and, consequently, different values of accuracy. This means that the transect must be chosen carefully in order to obtain realistic values of the depth.

Lastly, concerning the accuracy on the check points in the depth range $0-20 \mathrm{~m}$ (see Table 8), the value of the RMSE is few meters. However, using the band ratio methods, it is possible to carry out the bathymetry data on a large area, in less time and in a cheaper way compared to other bathymetric technologies.

\section{ACKNOWLEDGEMENTS}

This research was part of the "Development of synthetic optical sensors to support data fusion techniques applied to remote sensing images from aircraft, satellite and UAV", a research project supported by Campania Region (PO FSE CAMPANIA 2014-2020 - ASSE III) and the University of Naples "Parthenope".

In addition, we would like to thank the anonymous reviewers for their detailed comments and suggestions for the manuscript.

\section{REFERENCES}

[1] S. D. Jawak, S.S. Vadlamani, A. J. Luis. A synoptic review on deriving bathymetry information using remote sensing technologies: models, methods and comparisons. Advances in Remote Sensing, 4(02):147, 2015.

[2] X. Monteys, P. Harris, S. Caloca, C. Cahalane. Spatial prediction of coastal bathymetry based on multispectral satellite imagery and multibeam data. Remote Sensing, 7(10):13782-13806, 2015.

[3] D.R Lyzenga. Remote sensing of bottom reflectance and water attenuation parameters in shallow water using aircraft and Landsat data. Int. J. Remote Sensing, 2:71-82, 1981.

[4] S. Liu, J. Zang, J., Y. Ma, Bathymetric ability of SPOT-5 multi-spectral image in shallow coastal water. In Proceedings of 18th IEEE International Conference on Geoinformatics, Beijing, China, pp. 1-5, 2010.

[5] M. Lyons, S. Phinn, C. Roelfsema. Integrating Quickbird multi-spectral satellite and field data: mapping bathymetry, seagrass cover, seagrass species and change in Moreton Bay. Australia in 2004 and 2007. Remote Sensing, 3:42-64, 2011.
[6] G. Doxani, M. Papadopoulou, P. Lafazani, C. Pikridas, M. Tsakiri-Strati. Shallow-water bathymetry over variable bottom types using multispectral Worldview-2 image. International Archives of the Photogrammetry, Remote Sensing and Spatial Information Sciences, 39(8):159-164, 2012.

[7] M. Niroumand-Jadidi, A Vitti. Optimal band ratio analysis of worldview-3 imagery for bathymetry of shallow rivers (case study: Sarca river, Italy). ISPRS-International Archives of the Photogrammetry, Remote Sensing and Spatial Information Sciences, 8:361-364, 2016.

[8] D. Mulawa, C. Comp. Geolocation Accuracy Performance of the DigitalGlobe Constellation During 2015. The joint agency commercial imagery evaluation (JACIE) workshop, Fort Worth, Texas, USA, 2016.

[9] C. Parente, M. Pepe. Influence of the weights in IHS and Brovey methods for pan-sharpening WorldView-3 satellite images. International Journal of Engineering \& Technology, [S.l.], 6(3):71-77, 2017.

[10] DigitalGlobe, 2014, Geolocation Accuracy of WorldView Products. http://global.digitalglobe.com/sites/default/ files/WorldView_Geolocation_Accuracy.pdf [2017-07-16].

[11] S. Pe'eri, C. Azuike, C. Parrish. Satellite-derived bathymetry a reconnaissance tool for hydrography. Center for coastal ocean mapping. Hydro International, pp. $16-17,2013$.

[12] S. D. Jawak, A. J. Luis. A comprehensive evaluation of PAN-sharpening algorithms coupled with resampling methods for image synthesis of very high resolution remotely sensed satellite data. Advances in Remote Sensing, 2(04), 332, 2013.

[13] S.K. McFeeters, The use of the Normalized Difference Water Index (NDWI) in the delineation of open water features. Int. J. Remote Sensing, 17:1425-1432, 1996.

[14] S. D. Jawak, A. J. Luis. A spectral index ratio-based Antarctic land-cover mapping using hyperspatial 8-band WorldView-2 imagery. Polar Science, 7(1):18-38, 2013. ISSN 1873-9652, DOI:10.1016/j.polar.2012.12.002

[15] S. D. Jawak, A. J. Luis. A semiautomatic extraction of Antarctic lake features using WorldView-2 imagery, Photogrammetric Engineering \& Remote Sensing, 80(10):939-952, 2014. DOI: 10.14358/PERS.80.10939.

[16] P.E. Dennison, D.A. Roberts, S. H. Peterson, J. Rechel. Use of normalized difference water index for monitoring live fuel moisture. International journal of Remote Sensing, 26(5):1035-1042, 2005.

[17] Z. Xiaocheng, J, Tamas, C. Chongcheng, W.V. Malgorzata. Urban Land Cover Mapping Based on Object Oriented Classification Using WorldView 2 Satellite Remote Sensing Images. In Proceedings of International Scientific Conference on Sustainable Development \& Ecological Footprint, Sopron, Hungary, 2012.

[18] R. P. Stumpf, K. Holderied, M. Sinclair. Determination of water depth with high-resolution satellite imagery over variable bottom types. Limnology and Oceanography, 48(1part2):547-556, 2003. 
[19] R. Richter, D. Schläpfer. Atmospheric/topographic correction for satellite imagery. DLR report DLR-IB, pp. 565-01, 2005.

[20] DigitalGlobe, 2017. Radiometric Use of WorldView-3 Imagery. Technical Note,

https://dg-cms-uploads-production.s3.amazonaws. com/uploads/document/file/207/Radiometric_Use_ of_WorldView-3_v2.pdf [2017-07-16].

[21] M. A. Kuester, M. Ochoa, A. Dayer, J. Levin, D. Aaron, D. L Helder, L. Leigh, J. Czapla-Meyers, N. Anderson, B. Bader, F. Pacifici, W. Baugh, M.

Karspeck, N. Longbotham, and G. Miecznik. Absolute Radiometric Calibration of the DigitalGlobe Fleet and updates on the new WorldView-3 Sensor Suite, In Report of JACIE Civil Commercial Imagery Evaluation Workshop of DigitalGlobe Inc.; DigitalGlobe Inc.: Westminster, CO, USA, 2017.

[22] L. Gillen, C.J. Mugnier, P. Lucas, A. Walford. Photogrammetric Applications. Manual of Photogrammetry, Fifth Edition, American Society for Photogrammetry and Remote Sensing (edited by McGlone, J.C., Mikhail E.M., and J. Bethel), pages 509, 2004 .

[23] J. Martin, F. Eugenio, J. Marcello, A. Medina, J.A. Bermejo, M. Arbelo. Atmospheric correction models for high resolution WorldView-2 multispectral imagery: a case study in Canary Islands, Spain. In SPIE Remote Sensing. International Society for Optics and Photonics, 2012 .

[24] E. F. Vermote, N. El Saleous, C.O. Justice, Y.F. Kaufman, J.L. Privette, L. Remer, J. C. Roger, D. Tanre. Atmospheric correction of visible to middle infrared EOS-MODIS data over land surfaces: background, operational algorithm, and validation. J. Geophys. Res., D-102:17131-17141, 1997.

[25] P.A. Brivo, G. Lechi, E. Zilioli. Principi e metodi di telerilevamento. Città Studi Edizioni, Milano, 2006.

[26] B. C. Gao, M. J. Montes, Z. Ahmad, C.O. Davis. Atmospheric correction algorithm for hyperspectral remote sensing of ocean color from space. Applied Optics, 39:887-896, 2000.
[27] M. Pepe. Use of Digital Aerial Photogrammetry Sensors for Land Cover Classification, International Journal of Applied Engineering Research, 12(24):15610-15620, 2017.

[28] F. Eugenio, J. Marcello, J. Martin. High-resolution maps of bathymetry and benthic habitats in shallow-water environments using multispectral remote sensing imagery. IEEE Transactions on Geoscience and Remote Sensing, 53(7):3539-3549, 2015.

[29] C. Tarantino, F. Lovergine, G. Pasquariello, M. Adamo, P. Blonda V. Tomaselli. 8-band image data processing of the worldview-2 satellite in a wide area of applications. INTECH Open Access Publisher, 2012.

[30] A. Elsharkawy, M. Elhabiby, N. El-Sheimy, N. Improvement in the detection of land cover classes using the Worldview-2 imagery. In ASPRS, International Scientific Conference, pp. 19-23, 2012.

[31] S. Platnick, J. M. Fontenla. Model Calculations of Solar Spectral Irradiance in the 3.7- $\mu \mathrm{m}$ Band for Earth Remote Sensing Applications. Journal of Applied Meteorology and Climatology, 47(1):124-134, 2008.

[32] G. Thuillier, M. Hersé, T. Foujols, W. Peetermans, D. Gillotay, P. C. Simon, H. Mandel. The solar spectral irradiance from 200 to $2400 \mathrm{~nm}$ as measured by the SOLSPEC spectrometer from the ATLAS and EURECA missions. Solar Physics, 214(1):1-22, 2003.

[33] N.M Alsubaie. The Potential of Using Worldview-2 Imagery for Shallow Water Depth Mapping. PhD Thesis. University of Calgary, 2012.

[34] E. Green, A. Edwards P. Mumby. Mapping Bathymetry. In EDWARDS A. (ed.), Remote Sensing Handbook for Tropical Coastal Management, Paris, UNESCO, pp. 219-235, 2000.

[35] C.R. Rao. Linear Statistical Inference and its Applications, 2nd ed. New York: Wiley. 1973.

[36] P. Jagalingam, B. J. Akshaya, A. V. Hegde. Bathymetry Mapping Using Landsat 8 Satellite Imagery. Procedia Engineering, 116:560-566, 2015.

[37] J. S. Ehses, J. J. Rooney. Depth Derivation Using Multispectral WorldView-2 Satellite Imagery, 2012. 